\title{
An Approach for Description of Open Educational Resources based on Semantic Technologies
}

\author{
Nelson Piedra, Janneth Chicaiza, \\ Jorge López \\ Escuela Ciencias Computación \\ Universidad Técnica Particular \\ Loja, Ecuador \\ nopiedra, jachicaiza \& jalopez2 \\ [@utpl.edu.ec]
}

\author{
Oscar Martínez \\ Centro de Investigación Operativa \\ Universidad Miguel Hemández \\ Alicante, España \\ oscar martinez@umh.es
}

\author{
Edmundo Tovar Caro \\ Facultad de Informática \\ Universidad Politécnica de Madrid \\ Madrid, España \\ etovar@fi.upm.es
}

Abstract-Open Educational Resources are accessed through the web, whose real setting shows an explosion in the use and development of tools and services based on Social Software. However, the growth of this data repository makes it difficult to find information of value, and reduces the possibilities of sharing and exchanging resources. Using semantic technologies to describe educational resources enables any agent (human or software-based) to process and understand its content (applying inference rules on more structured knowledge). Metadata standards can be used to annotate educational resources; they facilitate their interoperability and discovery. In this work, we propose, OER-CC ontology, for the description of Open Educational Resources under Creative Commons Licenses. This approach is based on standard technology and metadata standards. The ontology could be utilized in higher education institutions (and organizations) to facilitate sharing and discovery of their digital content. This electronic document is a "live" template. The various components of your paper [title, text, heads, etc.] are already defined on the style sheet, as illustrated by the portions given in this document. (Abstract)

\section{INTRODUCITON}

Open Educational Resources (OERs) initiatives promote their global exchange with the ain of increasing the human intellectual capacity. The principal idea of the movement toward Open Educational Resources is that knowledge is a public good where technology in general, and specifically Web, provides an extraordinary opportumity for people to acquire key competences in a knowledge society while they share, use, and re-use digital contents

OER are teaching, learning. and research digital re-sources and tools (see Figure 1), available on the public domain or that have been released under an intellectual property license, that is, permit their fiee use, re-use or re-purposing by others.

The next level of educational technology infrastructure will need to use social tools and semantic technologies applied to the Web. The application of Social Web in OER projects has demonstrated that regular users can contribute content without specialist skills; any person can participate actively as an author in the Knowledge Society. By other hand, semantic Technologies enable the power of the semantic web for easy sharing, re-using and educational resources discover.

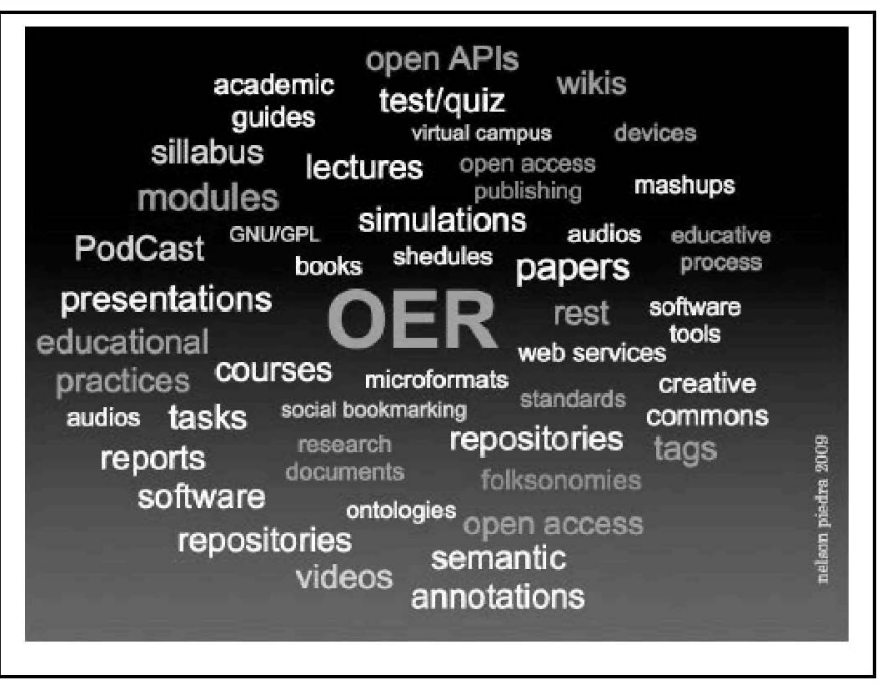

Figure 1. Open Educational Resources Map

In this paper, we propose, OER-CC ontology, for the description of Open Educational Resources under Creative Commons Licenses. This approach is based on standard technology and metadata standards. The ontology could be utilized in higher education institutions (and organizations) to facilitate sharing and discovery of their digital content.

This document is divided into 3 sections. The first section introduces the models and OER drivers and we put forward options for incorporating semantic technologies in OER description. Next, development process of OER-CC ontology is described: at each stage of ontology creation we argue the choice of each standard, tool and applied language. In the last section, we describe the recovery process of knowledge represented in ontology; several queries were designed to obtain information about the properties of the resources generated in the Computer Science School (CSS) of the 
Technical University of Loja (UTPL, Universidad Técnica Parficular de Loja - Ecuador).

\section{DESCRPIION OF OPEN EDUCATIONAL RESOURCES (OERS) BY MEAN OF METADATA AND ONTOLOGES}

The Open Educational Resources Initiatives are based on the Open Access (OA) movement.

Declauations of support for OA have been developed to accelerate efforts to promote open resources, technology and teaching practices in education. The Declaration of the Budapest Open Access Initiative [1] (BOAI, 2002) was among the first to strongly promote the open and free access to academic and research contents.

In the same way, importance of OER has been promoted by intemational and national organizations initiatives. Some of these initiatives are: Massachusetts Instute of Technology (MIT) in 2001 with its project OpenCourseWare and the OCW Consortium [2], projects from OECD's Centre for Educational Research and Innovation [4], UNESCO Initiative through Intemational Institute for Educational Planning [5], the Open University's Open Learn Project ${ }^{1}$. Universia MIT OCW Spain $^{2}$ and IEEE-Signal Processing Society ${ }^{3}$ will be wouk with the open-access repository project Comexions. Other initiatives can be found on the Wiki of the UNESCO OER Conununity ${ }^{4}$.

OER Projects can be classified according to model (funding. technical, content and staffing) used to ensure their sustainability. Downes in [3] describes each of the models.

In this paper, we focus on staffing models, that is, by the degree to which participants could actually help with resources. Considering this point of view, there are two models: producerconsuner and co-production [4] (we can find a comparison between them in the Wiki community project, WikiEducator ${ }^{5}$ ).

In producer-consumer models (or user-producer), an institution or consontum develop materials and release courseware under an open license, which can be reused by other providers. Within this group the MIT OpenCourseWare can be considered

Co-production models encourage open and unrestricted participation. aimed to leverage the benefits of masscollaboration and the principles of self-organization. This model, can promote the collaborative production of common resomces

The co-production strategies to OER production can be deployed using Social Web tools. The Web 2.0 or Social Web is focused in the contents, relationships and knowledge but not specifically in technology. As Will Richardson [6]. [7] writes: "The good news for all of us is that today, anyone can become an all life student. (Yes, even you.) Those technologies are easy to use in a way that was not possible in the past".

\footnotetext{
I http://openleam.open.ac.uk

2 http://mit.ocw.universia.net/

3 http:/heeecnx.org/

${ }^{4}$ http://oerwili.iiep -unesco.org/

http://wilieducator.org
}

The use of wikis is a good example of mansition fom static and restricted web sites to social and collaborative participation (co-authors). O'Reilly refers to Wikipedia as "a radical experience of confidence" [8]. Wikipedia, blogs and other tools allow the user to publish and then the comununity determines the relevance and pertinence of the content; mistakes are solved by social correction and with the support of content configuration management (version control)

The core strength of the social software is its easy use, however a OERs co-production model based on this kind of services have some weaknesses: Redecker in [13] identifies the main risks, barriers and obstacles to the implementation of Web 2.0 into teaching and leaming practice. Besides those points, we also believe that one of the greatest difficulties to adopt this approach is that the use of social tools is generating an impressive growing in the quantity of contents that are available in the internet. This situation is hindering the organization, retrieval and resources interoperability and its "intelligent" processing is required. Using semantic technologies we can provide a more explicit meaning to information, so that computers can understand and generate new knowledge by applying rules of inference to a better structured knowledge

\section{A. Incorporating semantics in OER Production}

These days, the use of semantic technologies and applications development of the Semantic Web (SW) in the leaning context, are the focus of researchers, organizations, universities and consortiums.

Semantic technologies will automate or semi-automate certain educative tasks trough "synergy between human and machines" (see Figure 2). Thus is explained by Gruber in [14] "Clearly, there are different roles for people and machines. People are the producers and customers: they are the source of knowledge, and they have real world problems and interests. Machines are the enablers: they store and remember data, search and combine data, and draw mathematical and logical inferences". With the incosporation of web semantic technologies in processes of creation, storage, retrieval and educational resources remix we expect a reduction in workload of those who run the leaming process.

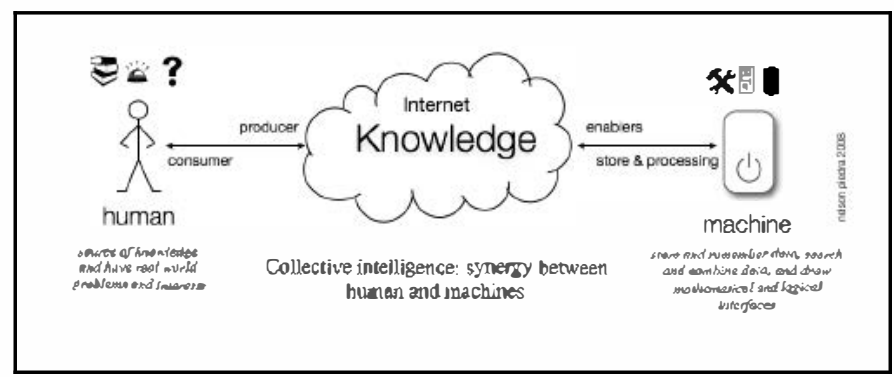

Figure 2. Synergy between tuman and machines

The Koper's study [15] showed application areas of the SW in education, he talk about will help to educators to perfoum some of their tasks such as settings, assessment and 
management and courses administration. We also think that the Semantic Web will enable to:

- identify more easily resources with particular properties or that have a kind of specific relationship with others;

- use of semantic rules, it can be a good support for interpretation and argumentation of several issues;

- suppliers of educational contents that use semantic technologies improve the administration, exchange and integration of resources with other information suppliers;

- bear a great potential of providing a robust and extensible base for emerging Social Web applications; interchange, distribution, and reuse of OER can be greatly facilitated by the infrastructures that the Semantic Web offers.

To achieve these objectives, educational resources should be described by a standard schema in a way that any agent (human or software-based) can understand and processing its content

\section{1) Metadata Standards for Educational Material}

Al-Khalifa and Davis as said in [24] "Metadata standards are formal specifications used to semantically annotate educational material of any king. They have been developed to support both machine interoperability (information exchange) and resource discovery by human users". Some metadata schemes allow the description of resources in XML, RDF, RDFa, or even OWL.

For the learning materials "these various standards and specifications have been developed to meet different requirements and to support the needs of different communities" [16]. Three are most recognized metadata standards:

- The IEEE LTSC (Leaming Technology Standards Committee) developed IEEE LOM ${ }^{6}$ (Leaming Object Metadata).

- The IMS GLC (Global Learning Consortium) proposes IMS Leaming Resource Metadata ${ }^{7}$.

- Dublin Core Metadata Initiative ${ }^{8}$.

The structure proposed by these standards is similar; each one has categories and each category contains a set of metadata. Depending on application, we can choose a subset or extend' the set with more metadata (the out-come of this adaptation process is called "metadata application profile"). Given the effort required to describe an educational resource using each characteristic proposed by those standards, we could create an profile for describe OERs, considering the particularities of this type of resource, such as:

\footnotetext{
${ }^{6}$ http://ltsc.ieee.org/wg12

${ }^{7}$ http://www.imsglobal.org/metadata/index.html

${ }^{8} \mathrm{http}: / /$ dublincore.org

'According to level of granularity and required interoperability
}

- Some projects are based on social software, there-fore, metadata about the social tools, type of re-source and resource annotations (using social classification systems, such as, folksonomies) are required.

- Open educational resources are licensed under copyleft licenses such as Creative Commons (CC) or GPU/GPL, therefore, metadata about licensing is needed to determine what is permitted, required or prohibited in a work.

\section{2) Ontologies}

According to Gruber's definition [11], an ontology specifies the conceptualization of a specific domain in terms of concepts, attributes, and relationships [12]; also it should be expressed in a formal language "so that a given ontology expression can be interpreted and processed" [18]. Unlike other knowledge structures (e.g. library classification or thesaurus), an ontology allows applying logic, inheritance and other issues [17].

In 1997 emerged the first language for ontologies $\mathrm{SHOE}^{1 \bullet}$ (Simple HTML Ontology Extensions), so far some languages have been proposed to be more complete and less complex languages than their predecessors. Nowadays the languages most used are RDF and OWL; one of limitations of RDF is that it is not expressive enough to represent complex ontologies, while that OWL extends the possibility of using logical expressions to describe complex concepts and relationships.

The modeling of domain knowledge can be done us-ing traditional paradigms and tools, UML (Unified Modeling Language) or database technologies. But as stated Gomez et al. [19] "...the formalisms used to model the domain knowledge and the languages that implement these techniques limit the kind of knowledge that can be modeled and implemented", i. e. "only allow the representation of lightweight ontologies". Consequently to modeling of large or complex domains have been proposed several approaches that allow us develop ontologies ("heavyweight ontologies") based on Artificial Intelligence (AI) formalisms; so we have better control over the vocabulary and the semantic. In [19] a comparative study between these three paradigms can be found.

There are several methodologies for building ontologies, two of them could be regarded as more mature a) METHONTOLOGY, proposed by Gómez-Pérez et al. in 1996; and b) On-To-Knowledge, proposed in 2001 by Staab et al.

Regardless of the methodology used to create the ontology, its design should be guided by the Gruber's principles: clarity, coherence, extendibility, minimal encoding bias and minimal ontological commitment; the idea is to ensure the "knowledge sharing" [21]. To fulfill these criteria, ontology evaluation should be performed at the same time as the development-oriented activities. Different type of evaluation could be made [23]: a) Syntactic evaluation, to check languages specification b) Semantic evaluation, focused on detecting if the ontologies have inconsistencies and redundancies c) Lexical evaluation, it refers to the vocabulary used to represent concepts and domain relationships. Other

10 www.cs.umd.edu/projects/plus/SHOE 
issues related to evaluation are presented in the Brank's et al. [25] paper.

\section{B. Related Work}

We have found several works that involve the development of ontologies for a specific issue of e-leaming or to modeling knowledge related to a specific problem.

\section{1) Ontology for e-learning system}

Ghaleb et al. in [12] developed an ontology for web-based e-leaming system of Qatar University. End-user can annotate leauning resources by means of Web form: the system converts this information to a set of RDF statements using the RAP API (Semantic Web toolkit for PHP developers). According to the authors "the ontology can be used for adaptive leaming to retrieve the context of a course and to structure the contents". Their model includes a service of simple semantic search.

This work cannot be reusable in OER domain because it isn't metadata standards-based (or there isn't information) and the ontology model hasn' $t$ been published.

2) Application ontologies for assembling learning objects

Santacruz in [26], [22] put forward OntoGlue, "an ontology-based mechanism for assembling leaming objects". In order to assemble two leaming objects, the requirements of one must be covered by the competencies of the other. The problem resolved by OntoGlue is the semantic comparison (considering that one requirement and one competence can't be syntac-tically equal, but the semantics is the same) among concepts, since mappings between ontologies are established. The standard LOM is used to describe ELOs (Electronic Leaming Objects) although an extension that has been included.

\section{3) Metadata Standards for describing Objects and} Learning Resources

For semantic representation of Learming Objects. Fernoso et al in [20] put forward the ontology LOM2OWL ${ }^{11}$, its structure allows to describe LOs using IEEE LOM standard. Later, we will refer to this work.

For description of Learning Resources. Brown and Thomas explain in [9] metadata approach within the OER project "The Open Polytechnic of New Zealand". They created an application profile that contains necessary elements to ensure metadata interoperability "with both a national and an nitemational audience", thus, 15 metadata was chosen of those 5 belongs to Educational Category. However, this work doesn't consider projects social software-based neither the licensing issue.

For description of works licensed under Creative Cormmons (CC). In 2008, CC published the metadata standard ccREL ${ }^{12}$ (Creative Commons Rights Expression Language), it that aims to "make licensed works more reusable and easy to find". To date ccREL metadata, as encoded using RDFa or XMP.

\footnotetext{
${ }^{11} \mathrm{http} / /$ www.cc. uah.es/ie/ontologies.html

$12 \mathrm{http}$-//wilin. creativecommons.org/CcREL
}

\section{DEVELOPMENT OF OER-CC ONTOLOGY}

In this section, authors introduce details dealing with the implemented ontology to model the OER and CC domains. Thus, research team tried to achieve the following main goals: (i) to describe $\mathrm{OER}$ and $\mathrm{CC}$ resources using a conumon vocabulary by users and producers, i.e., an implemented ontology offered to students and lecturers within an educational context respectively, and (ii) to automate execution of tasks for selected domains such as information retrieval using semantic techniques

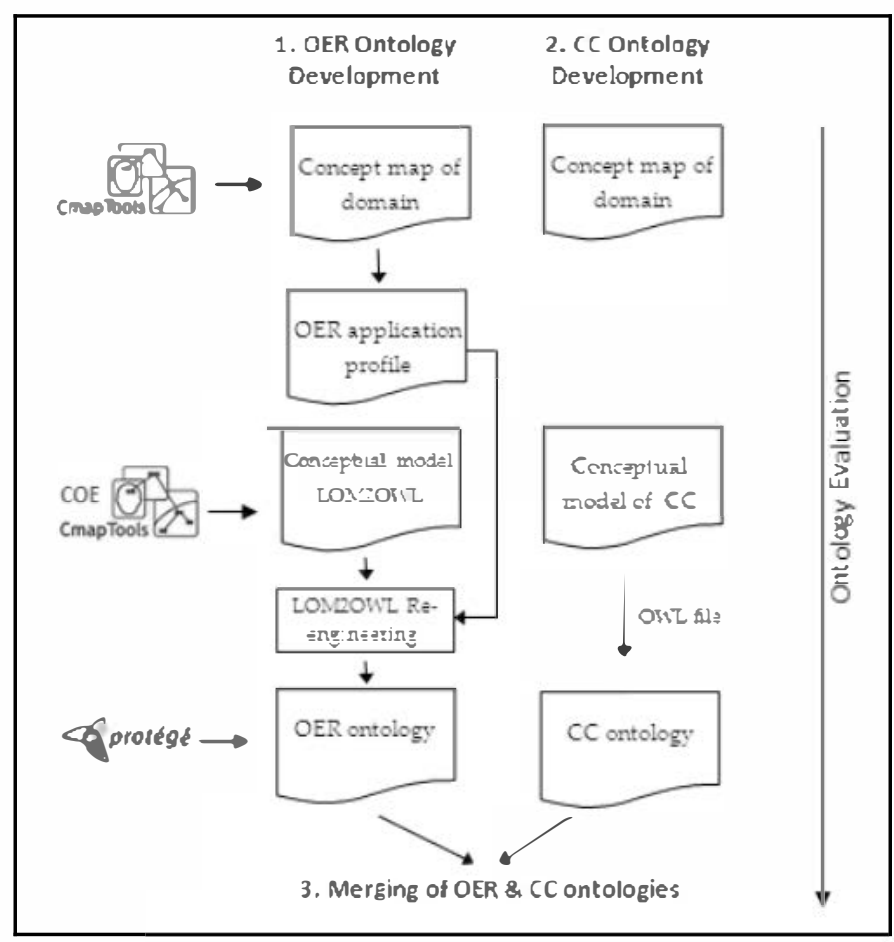

Figure 3. Process and tools for ontology development

\section{A. Process and tools to build ER-CC ontologv}

Ihen, development process of our OER-CC ontology was divided into three general phases:

1) OER ontology development. At this point, we started with an initial ontology (LOM2OWL ${ }^{13}$ ) adapted to the metadata requirements for OERs (based on IEEE LOM).

2) CC ontologv development. In this case, CC ontology was designed using METHONTOLOGY [19] guidelines.

3) Merging of CC and OER ontølogies. Finally, we unified concepts, terminology, definitions and constraints from the two source ontologies.

\section{B. Development process}

As introduced before, development process was based on METHONTOLOGY [19] guidelines. This method proposes an ontology building life cycle based on evolving prototypes. That is, it allows adding, changing, and removing terns in each new version (prototype). Next, figure 3 depicts the development process and used tools through each phase respectively.

${ }^{13}$ http-//www.cc. uah.es/ie/ontologiaLOM2OWL/LOM2OWL.owl 
Therefore, we started the development process creating concept maps for both knowledge domains respectively. For this purpose, we depicted main points of OER-CC ontology with a general study of references to describe metadata of selected domains. As a consequence, we evaluated some wellknown references to describe OER metadata like IEEE-LOM [30] and Dublin-Core (DC) [31]. At this point, we understand that IEEE-LOM introduces enough metadata to characterize our educational purposes for this work. In addition, IEEELOM was used because we think that it includes large amount of structured metadata into different categories, allowing greater semantic flexibility for our selected domains. Another important issue was that it is a leading standard within eleaming environments [16] usually.

Then, all metadata associated with $\mathrm{CC}$ licenses was represented considering the ccREL standard [10] which provides information related to Licenses Properties, e.g., permissions, prohibitions, requirements and general metadata. Once we had decided how to describe metadata, we selected well-referenced tools to model the OER-CC ontology successfully. Concretely, we used the following:

- CMaptools [28] was used to represent and internconnect both knowledge domains, i.e., OER and CC respectively. In addition, Cmaptools Ontology Editor ${ }^{14}$ (COE) was used for constructing, sharing and viewing modeled ontology based on CmapTools. Besides, this allowed preparing OER-CC ontology to be modeled using $\mathbf{O W L ^ { 1 5 }}$ language.

- Protégé [29] was used to implement our ontology formally. For this purpose, all prior results were imported to this ontology editor. Then, we used SWRL $^{16}$ to provide deductive reasoning capabilities and $\mathbf{S P A R Q L} \mathbf{L}^{17}$ to retrieve the educational resources metadata.

Each tool and language was applied at different stages of process.

Additionally, each prototype of OER-CC ontology was validated through evaluation items like: (i) Syntactic evaluation, by mean of Pellet reasoner ${ }^{18}$ and syntax checker used for this work, (ii) Taxonomy evaluation, at this point we validated standard rules in taxonomies like inconsistency, incompleteness and redundancy in concepts respectively. Once we finished the development process successfully, we were ready to deploy OER-CC ontology. Therefore, next section introduces details that give preliminary evidences of our contribution in this work.

\section{OER-CC ONTOLOGY InSTANTIATION AND RETRIEVAL}

Then the formalization and implementation activities are carried out, in this last section, we attempt to provide a piece of

\footnotetext{
14 http://coe.ihmc.us/groups/coe/

15 http://www.w3.org/TR/owl-ref/

16 http://www.w3.org/Submission/SWRL/

${ }^{17}$ http://www.w3.org/TR/rdf-sparql-query/

18 http://clarkparsia.com/pellet/
}

the true potential of ontologies use to represent domains in the context of Education and particularly to describe OERs, i e.

- The machines can understand and interpret meaning of educational content, thus facilitate or automate execution of certain tasks, such as, accessibility or retrieval with the contents of both domains.

- Users and OER producers ${ }^{19}$ can use a common vocabulary to describe their resources; it enables to reuse and to share application domain knowledge.

- Represent a metadata structure through ontology; it will enable interoperability among different do-mains (vocabularies). This promotes accessibility and OERs sharing between universities and organizations around the world.

One of the ways we use to demonstrate that potential is defining and executing queries and inference rules on OER-CC ontology to retrieval and to exploit its knowledge. Before discussing the results, we explain the filling the ontology with resources metadata produced in a higher institution.

\section{A. Instantiation process and tools}

Once the ontology is built, the process of ontology population starts, and then it allows extracting relevant information from the resources hosted by ontology. The population process "consists in creating a knowledge base containing instances of the ontology concepts and instances of the ontology relations" [19].

This process can occur in 3 ways, depending on the level of automation is required or that it can be applied. This process can occur in 3 ways, depending on the level of automation is required or that it can be applied.

1. Manual. This mechanism may be viable when we have a small number of instances for each concept and it can be done through ontology development tools and tool suites; they provide basic support for the ontology population so that ontology developers can create instances with their ontology editors [19].

2. Semi-automatic, applying automatic leaming techniques on sources of unstructured or data semi-structured.

3. Automatic, creating specific applications (using ontology management APIs) to generate in-stances from structured data sources and directly insert them in each concept.

For the OWL ontology population, Protégé offers certain plugins.

- DataMaster ${ }^{20}$, to import schema structure and data from relational databases into Protégé.

\footnotetext{
19 The role of users and OERs producers change depending on adopted production model. In a user-producer model, students consume re-sources and institutions generate them; while a co-production model anyone participant (including students and self-learner) can contribute to creating them

20 http://protegewiki.stanford.edu/index.php/DataMaster
} 
- XML Tab ${ }^{21}$, to import an XML document into Protégé, creating a set of classes and instances in a knowledge base which correspond to the entries in the XML document.

- Excel Import ${ }^{22}$, to import content and classes from Excel or CSV files, it available so far only for Protégé 4.0 .

In all cases, the data source must be in a structured format and classes are created according to this structure. When the ontological model has been implemented a process is required to move instances from the new classes to existing classes.

\section{B. OER-CC Ontology Instantation}

To instantiate the OER-CC ontology, we considered some resources generated in the Computer Science School (CSS) of the Technical University of Loja (Universidad Técnica Particular de Loja ${ }^{23}$, UTPL-Ecuador).

UTPL are using social software for knowledge management, leaming and OER development based on a coproduction model. From 2008, the School has opened completely all the training courses of Engineering free of charge; this has enabled the exchange of experiences internally and with other academic units.

A manual process has been developed to populate the OERCC ontology with the CSS' educational resources, because Protégé plugins import schema structure and data from structured sources (unlike what is required in this work since we already have the model). Concretely, those resources are videos and keynotes authored by teachers and students basically. In addition, they are available on youtube ${ }^{24}$ and slideshare ${ }^{25}$ of the School's channels also. Furthermore, instantiation dealing with $\mathrm{CC}$ domain was considered using different types of Creative Commons Licenses with jurisdiction in Ecuador ${ }^{26}$.

\section{Information Retrieval}

As introduced in section 3.2 we used SPARQL language to retrieve knowledge represented at our OER-CC ontology. Thus, we developed some queries to retrieve information, e.g., properties of OERs and CC licenses.

What is more, our initial results show that our OER-CC ontology has been deployed successfully, i.e., using metadata from initial instantiation of educational objects.

Some queries were designed to extract information from OER-CC ontology, geared mainly to determine its use in tasks of recovery, accessibility and OERs re-mix.

\footnotetext{
${ }^{21}$ http://protegewiki.stanford.edu/index.php/XML_Tab

22 http://protegewiki.stanford.edu/index.php/Excel_Import

23 www.utpl.edu.ec

${ }^{24}$ http://www.youtube.com/eccutpl

25 http://www.slideshare.net/eccutpl

${ }^{26}$ http://creativecommons.ec/
}

Table I and Table II list some competency questions that can be answered by the ontology. SPARQL panel of Protégé was used to run queries, the next step is to develop or integrate applications (software agents or web services) that implement the above activities.

As shown in Table I, one of the advantages of using OER$\mathrm{CC}$ ontology and the IEEE-LOM standard is that we can complete information for each resource metadata in various languages and thus facilitates multilingual search.

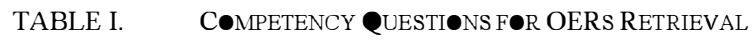

More specific searches can be constructed by applying filters (assembling different types of combinations) on different OERs properties.

Multilingual search. If multilingual descriptions of metadata were specified

Competency questions

$¿$ What is general information of an educational resource (title, description, keywords, and other metadata)?

What educational resources are labeled with a particular word? Such questions are especially common in a co-production model in which multiple annotators can add, in a simple way, tags to each resource. The tags could be used to improve search results as proposed in [27].

TABLE II. C@MPETENCY QUESTI NS F $\bullet$ ACCESIBILITY AND REMIX

- We can exploit the information on licensing, contribution and attribution to facilitate accessibility and OERs re-mix Competency questions

What are the resources created by a particular contributor and what type of contribution have done?

What are the direct contributions of a university in the OERs production and what are indirect contributions through their teachers / students?

Who should be given attribution and under what conditions we can make use of OERs?

What are all contributors (individual and organizational / institutional) of a specific OER?

What kind of licenses we use to can generate educational resources in a country and under what conditions these can be remixed?

How can access (URI or URL) to an OER and how it can display (depending on the type of resource)?

What educational use and in what context we can use an OER?

Next, we introduce a implemented query (to answer the question: what are the direct contributions of the UTPL in the OERs production and what are indirect contributions through their teachers/students, see Figure 4) within OER-CC ontology.

These queries results confirm that a short-term improvement in information retrieval task can be achieved considering educational resources generated at the Computer Science School of the UTPL. 


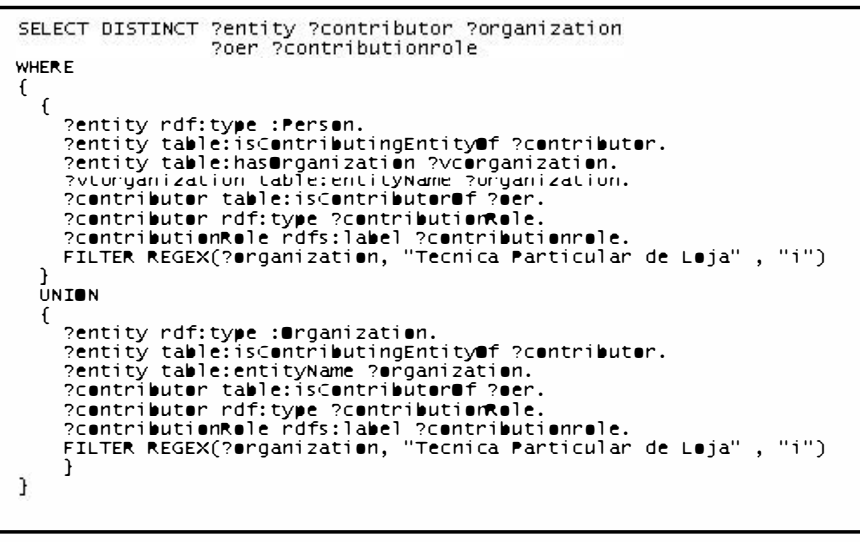

Figure 4. Query for rexcieval UTPL contributions

\section{CONCLUSION}

In this work, we have given initial evidences that machines could understand and interpret semantic meaning of educational contents.

As a main contribution, we have implemented OER-CC ontology to model knowledge dealing with OER and CC domains respectively. Therefore, we have been able to inference knowledge using OER-CC ontology, i.e., thorough instantiation and classification of educational objects respectively. About work in progress, research team continues working to improve OER-CC ontology deployment. Currently, we are involved with more methods to promote accessibility according to OER user requirements; e.g., the content of an educational resource could be ranked within the OER-CC ontology according to student / lecturer profile respectively.

Furthernore, this work has enabled us to implement ontologies from concept maps (process used to generate CC ontology). With the support of easy-to-use graphical tools (as Cmaptools) could massify development of ontologies, with the additional advantage it may include domain-experts.

\section{ACKNOWLEDCMENT}

Support for this work was provided by UPM under project AL09-PD-36, UTPL and scholarship provided by the Secretaria Nacional de Ciencia y Tecnologia (SENACYT) of Ecuador.

Our thanks to eMadrid Consortium. Authors are members of GICAC-UPM that is part of eMadrid consortium.

\section{REFERENCES}

[1] BOAI. (2002). Declaration of the Budapest Open Access Initiative (Tech. Rep.). Online http-//www. soros.org/openaccess/

[2] MIT-OCW. (2001). MIT OpenCourseWare. Massachusets Institute of Technology. Online http://ocw.mit.edu/.

[3] Downes S. "Models for Suswinable Open Educamional Re-sources". Interdisciplinary Journal of Knowledge and Learn-ing Objects, vol 3, 2007.
[4] OECD, "Giving Knowledge for Free. The Emergence of Open Educational Resources". Centre for Educational Research and Innovation (CERI), 2007. (Book style)

[5] IIEP (2005-2008). International institute for educational planning community of interest on open educational resources, online http://oerwilk iiep-unesco.org. (Tech. Rep.). UNESCO

[6] Richardson W. (2006a). Blogs, wikis, podcasts and other powerfil web tools for classrooms. Corwin Press.

[7] W. Richardson (2006b, October). The new face of learning (Tech. Rep. No. 164). Edutopia.

[8] O'Reilly T. (2005). What is web 2.0? design patterns and business models for the next generation of software. (Tech. Rep.). O'Reilly Network

[9] Brown, C., \& Thomas, B. (2007). "Metadata decision for the OER Project". The Open Polytechnic of New Zealand.

[10] Creative Commons, "ccREll: The Creative Commons Rights Expression Language", 2008.2 Online. http-//wili. creative commons.org/images/d/d6/Ccrel-1.0.pdf

[11] Gruber, T. "A translation approach to portable ontology specifications", Stunford University, 1993. International Journal of Human-Computer Studies, pages 43(5/6):907-928.

[12] Ghaleb, F., Daoud, S., Hasna, A., ALJa'am, J. M., El-Seoud, S. A., \& El-Sofany, H., "E-Learning Model Based On Semantic Web Technology", International Journal of Computing i\& Information Sciences, 2006, pp. 63-71

[13] S. Schaffert, "Semantic social software: Sernantically enabled social software or socially enabled semantic web?", In Proceedings of the SEMANIICS 2006 conference, pp 99-112, Vienna, Austria, Nov 2006. (Book style)

[14] Gruber, T. "Collective knowledge systems: Where the social web meets the semantic web". Online http-//tomgnber org/writing/CollectiveKnowledgeSystems.pdf. 2007. (URL link *include year)

[15] Koper, $R$ "Use of the semantic web to solve some basic problems in ducation", Journal of Interactive Media in Education, May 2004. (Journal or magarine citation)

[16] Nilsson, M., Johnston, P., Naeve, A., \& Powell, A. (2006). "The Future of Learning Object Mendata. Towards an Interoperability Framework for Metada Standards" (Tech report).

[17] Qiv, J., "Developing Ontologies for Information Representa-ion and Access", SEDIC Panel, 2008.

[18] Kim, H. "Predicting how ontologies for the semantic web will evolve". Communications of the ACM, vol. 45, pp. 48-54, 2008.

[19] Gómez-Pérez, A. Fernández-López, M. and Corcho, O. "Ontological Engineering". ISBN 1-85233-551-3. Springer-Verlag, 2002. (Book style with editor)

[20] Fermoso-Garcia, A. Alonso, S. \& Sicilia, M.A. 'Una ontolog-ía en OWL para la representación semántica de objetos de aprendizaje", 2008.

[21] Gruber, T. "Toward principles for the design of ontologies used for knowledge shaning". Knowledge Systems Laboratory, Stanford University, KSL 93-04, 1993. (Tech. Rep. with number)

[22] Santucruz, L. Navarro, A. Aedo L. \& Delgado, C. "An ontology-based mechanism for assembling learning object". IEEE Xplore, pp. 472477,2005

[23] Gómez-Pérez, A. \& Suárez-Figueroa, M. C. "Results of Tax-onomic Evaluation of RDF(S) and DAML +OIL Ontologies using RDF(S) and DAML $\ddagger$ OIL Validation Tools and Ontology Platforms Import Services". CEUR Worloshop Proceedings, vol 87, 2003.

[24] Al-Khalifa H. S. and Davis, H. C. "Replacing the monolithic LOM: A folksonomic approach", Advanced Learning Technologies, IEEE Internarional Conference on, vol. 0, pp. 665-669, 2007.

[25] Brank, J. Grobelnik, M. \& Madenic, D. "A Survey of Ontolo-gy Evaluation Techniques", Confoence on Dato Mining and Data Warehouses (SKKDD), 2005.

[26] Santruz, L. "Automatización de los procesos para la generación ensamblaje y reutilización de objetos de aprendizaje", Universidad Carlos III de Madrid, 2005. (Phd thesis). 
[27] Shenghua, B. Xiaoyuan, W. Ben, F. Zhong, S. and Yong, Y. "Optimizing web search using social annotations", WWW2007, 2007. [Online]. Available: www2007.org

[28] Institute for Human and Machine Cognition (IHMC). Cmap-Tools Home Page Cmap. Online http://cmap.ihmc.us/
[29] The Stanford University. Protégé home page. Online http://protege.stanford.edu

[30] LOM Learning Object Metadata http://ltsc.ieee.org/wg12/20020612-Final-LOM-Draft.html

[31] DC The Dublin Core Metadata Initiative http://dublincore.org/.
IEEE 
ANNEX 1 CONCEPTUAL MAP: Open Educational Resources Knowledge Domain

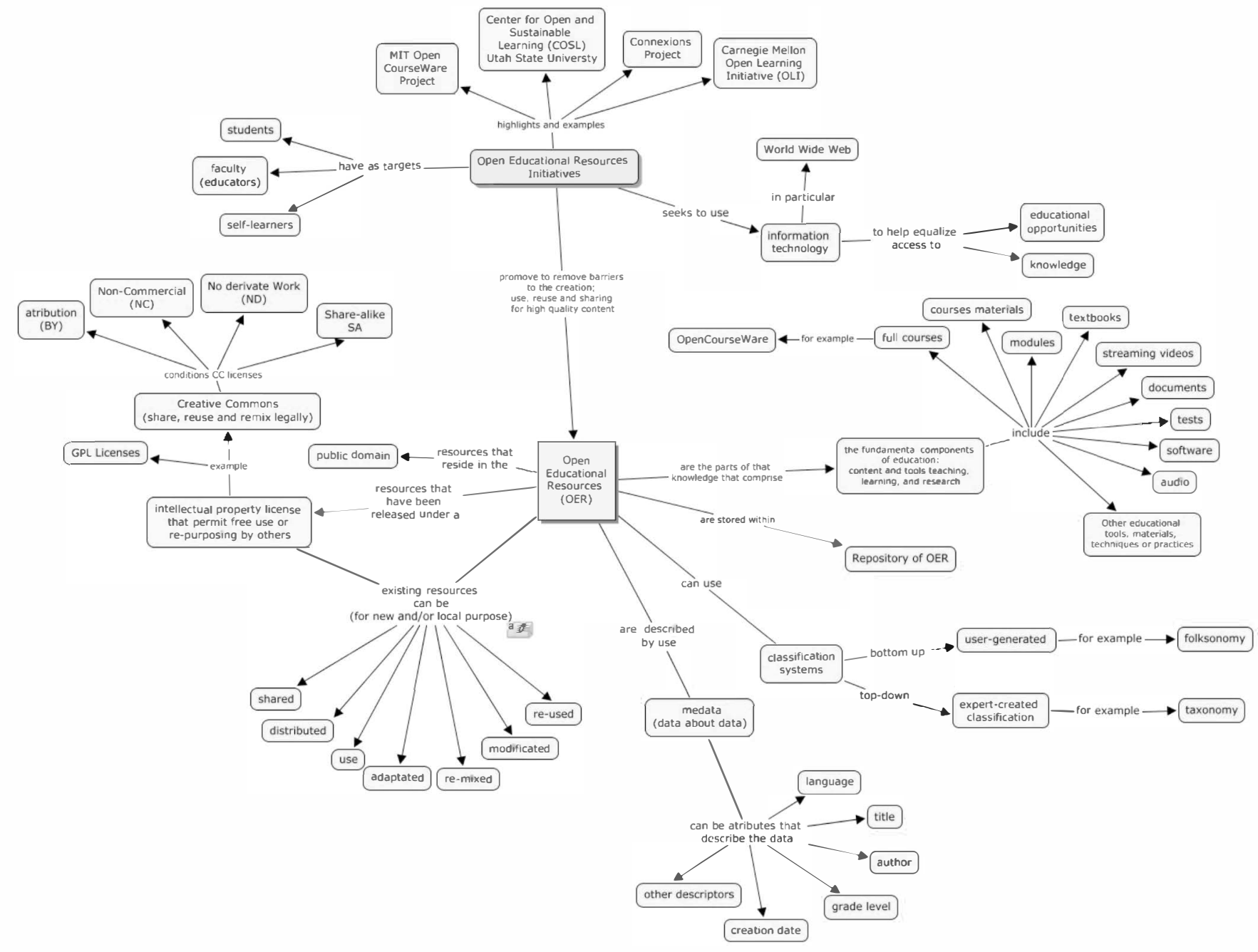

